\title{
Base oil oxidation detection using novel chemical sensors and impedance spectroscopy measurements
}

\author{
Mostafa Soleimani $^{\mathrm{a} *}$, Marios Sophocleous ${ }^{\mathrm{a}}$, Ling Wang ${ }^{\mathrm{a}}$, John Atkinson $^{\mathrm{a}}$, Ian L Hosier ${ }^{\mathrm{b}}$, \\ Alun S Vaughan ${ }^{\mathrm{b}}$, Robert I Taylor ${ }^{\mathrm{c}}$, Robert JK Wood ${ }^{\mathrm{a}}$ \\ ${ }^{\text {a }}$ Faculty of Engineering \& the Environment, University of Southampton, UK \\ ${ }^{\mathrm{b}}$ Faculty of Physical Sciences \& Engineering, University of Southampton, UK \\ ${ }^{c}$ Shell Research Ltd, Shell Technology Centre Thornton, P.O. Box 1, Chester, UK
}

\begin{abstract}
Lubricating oils are employed in machinery to minimise friction, remove heat and wear particles, protect against corrosion etc. Mineral base oils are derived from natural crude oil through a distillation process and are divided into five main groups depending on volume of sulphur, saturate and viscosity index, according to the American Petroleum Institute (API). As lubricating base oil oxidises, acidic by-products are formed and oil viscosity increases due to progressive polycondensation of higher molecular weight products. In this work, thick film (TF) potentiometric sensors based on ion-selective electrodes (ISE) have been developed for oil acidity measurement to enable online oil condition monitoring. A TF ruthenium oxide $\left(\mathrm{RuO}_{2}\right)$ working electrode and three types of TF reference electrodes were fabricated and tested in oxidised base oil samples prepared at the Shell Houston laboratories. The TF sensors were evaluated by comparison with acid number (AN) measurement and also compared with oil conductivity measurements using impedance spectroscopy. The results show that the conductivity, viscosity and AN of the oil samples increase with the level of oil oxidisation. The output of the TF sensors detected the acidity increase of the oxidised oil samples at both 50 and $80{ }^{\circ} \mathrm{C}$ and displayed a linear relationship with oil AN.
\end{abstract}

\section{Introduction}

Most modern lubricants used in industry and combustion engines are formulated from a range of base oils and additives. Base oils are produced by refining crude oil (mineral base oil) or through chemical synthesis (synthetic base oil) and primarily provide a fluid layer for the separation of moving parts, which removes heat and wear particles whilst minimizing friction ${ }^{1}$. Lubricants degrade during machinery operation and the degradation process is governed by many parameters in the system, such as pressure and operating temperature. Oil ageing occurs due to base oil oxidation, additive depletion and/or contamination, such as water ingress and fuel dilution.

Base oil oxidation is driven by oxygen and heat. At low temperature (below $120{ }^{\circ} \mathrm{C}$ ), it consists of four stages, including the slow radical chain reaction initiation stage at the beginning of oil oxidation process, forming alkyl radicals, the much faster irreversible radical chain propagation stage, then the chain branching stage and finally the radical chain termination stage. During the second, or the chain propagation stage, alkyl radicals formed in the initiation stage, react with oxygen forming peroxy radicals

\footnotetext{
* Corresponding author. Tel.: +44 2380593166.
}

E-mail address: m.soleimani@soton.ac.uk 
that subsequently abstract hydrogen from another hydrocarbon, to form a hydroperoxide and another radical. As hydroperoxides are produced and accumulated, the final or autoretardation starts, leading to the termination of the oil oxidation process ${ }^{1}$. Carboxylic acids produced during this process increases oil acidity. Also polymerisation byproducts formed during the termination stage cause an increase in oil viscosity ${ }^{1,2}$.

Oil acidity is usually measured using standard laboratory-based off line titration methods (e.g. ASTM D974-1240) that has been widely accepted by industry. A number of attempts have also been made to develop on-line chemical sensors for oil basicity ${ }^{3}$ and acidity monitoring, such as metal oxides ${ }^{4}$, infrared (IR) ${ }^{5}$ and mass sensitive quartz crystal microbalance $(\mathrm{QCM})^{6}$. However, there has not been any publication reporting commercially available online oil acidity sensors, due to the complexity of oil chemistry and the difficulties in simulating oil ageing in laboratories.

Laboratory-based oil condition monitoring has generally been carried out by taking oil samples regularly for lab analysis and providing information on oil condition for maintenance plans, which can be time consuming, costly and laborious. There are a number of laboratory oil analysis devices and techniques such as viscometers, infrared spectrometers, debris analysis techniques and electrochemical impedance spectroscopy (EIS). EIS provides electrochemical information that can be interpreted and modeled as an equivalent circuit (EC) and is widely used for the analysis of complex solid and liquids, such as oils. AC impedance spectroscopy has been used to measure the conductivity of industrial polymers and colloids, which are classified as lowconductivity and high resistance media ${ }^{7}$. Its feasibility in detecting contamination of industrial lubricants by water $^{8}$ and glycol leakage ${ }^{9}$ as well as diesel contamination by $\operatorname{soot}^{10}$, the influences of lubricant chemical compositions ${ }^{7}$, the effect of steel in jet engine oil ${ }^{11}$ and changes in industrial cutting fluids ${ }^{12}$ have also been investigated. As oil degrades, its electrical conductivity changes due to changes in the concentration of "conductive species" in the oil. Therefore, electrical properties are often used to assess the quality of oils. In this study, AC EIS has been performed for oxidised oil samples, in order to analyse the effects of oxidation processes on the physical and chemical properties of the base oil and to compare these results with the acidity measurements made using novel TF sensors.

A large amount of effort has been invested over the years to develop on-line oil condition monitoring sensors, e.g. sensors that can monitor oil viscosity ${ }^{13}$, debris ${ }^{14}$, $\operatorname{soot}^{15}$, fuel dilution ${ }^{16}$ and water-in-oil content ${ }^{17}$. Some of them were trialed in cars such as the dielectric measurements tested in Mercedes-Benz cars, but this was short lived and has not been widely adopted ${ }^{18}$.

Thick film (TF) sensor technology, introduced over 50 years ago, offers compact and low cost mass production for many applications. TF acidity sensors have been proved to be robust with good reproducibility for aqueous solutions acidity measurements ${ }^{19,20,21}$. An initial study using TF sensors in oxidised base oil and fully formulated engine oil samples with added acid showed that the TF sensors can respond to oil acidity changes ${ }^{22}$. This paper presents the results of the TF sensors in measuring the acidity of oxidised base oil samples that are compared with a range of measurement techniques, including AN, viscosity and oil conductivity using impedance spectroscopy method. 


\section{Experimental work}

\subsection{Oil samples}

Fresh and oxidised oil samples were prepared at the Shell Houston laboratories using a proprietary in-house blown $\mathrm{NOx}\left(\mathrm{BNO}_{\mathrm{X}}\right)$ oxidation test. During the oxidisation process, $350 \mathrm{ml}$ of Motiva Star 6 base oil, a group II base oil containing no additives (hydrotreated base oil composed of hydrocarbons) were heated to $155{ }^{\circ} \mathrm{C}$ whilst an air/ $\mathrm{NO}_{2}$ mixture $\left(\mathrm{NO}_{2}\right.$ concentration was $\left.3000 \mathrm{ppm}\right)$ was blown into the oil at 200 cc/min. Oil samples were taken at six oxidation intervals: 2, 4, 8, 16, 20 and 24 hours. Since the oil samples do not contain additives, the oil was extensively oxidised after 24 hours, whereupon the oil viscosity has increased significantly. On receiving the oil samples from the Shell laboratory, their AN values were measured using a Kittiwake test kit (FG-K1-110-KW) at room temperature, using colour-indicator titration, following ASTM D974-12 standard. Their viscosities were also measured using a Brookfield CAP2000 viscometer (cone and plate) at two temperatures $\left(50{ }^{\circ} \mathrm{C}\right.$ and $80{ }^{\circ} \mathrm{C}$ ) prior to being characterised using the EIS and TF techniques. The acidity of the fresh oil and the six oxidised samples was measured using TF ruthenium oxide working electrodes against a number of different TF reference electrodes. The water content of the oil samples was measured using a coulometric Karl Fischer titrator (Cou-Lo compact made by GR Scientific). The detail of the oxidised oil samples alongside AN and viscosity measurements is presented in Table 2 .

\subsection{Electrochemical Impedance Spectroscopy (EIS)}

Fresh lubricants are poor electrical conductors. As oil degrades, its electrical conductivity increases due to the increase in the concentration of conductive species such as nitric acid (oxidation by-products) and contaminants (e.g. metallic wear particles, water). Therefore, electrical properties such as permittivity, impedance and conductivity provide a potentially powerful means of assessing the quality of oils.

For this study, EIS tests were performed using a Solartron 1260 gain-phase frequency analyser model 1260A, connected to a Solartron dielectric interface model 1296A, controlled by a PC running Solartron "Smart" software permitting automated data collection. The test cell utilised is aluminium with a cup-plate geometry which has an electrode diameter of $42 \mathrm{~mm}$ and an electrode gap of $0.5 \mathrm{~mm}$ (spacer) requiring $3 \mathrm{ml}$ of oil, as illustrated in Figure 1. Impedance measurements were carried out at two temperatures $\left(50\right.$ and $80{ }^{\circ} \mathrm{C}$ ). Before each EIS measurement, 15 minutes were allowed to achieve a stabilised temperature. An AC voltage (100 mV RMS amplitude) was applied at a constant amplitude and the frequency was varied from $1 \mathrm{MHz}$ to $1 \mathrm{~Hz} .8$ points per decade were collected and the data were averaged over 10 cycles. The conductivity of the oil was calculated from the real-part of the complex impedance (i.e. resistance) and the cell constant (area and distance between two electrodes) using the equations below ${ }^{23}$ :

$$
R=\rho \frac{d}{A} \Rightarrow \sigma=\frac{1}{\rho}
$$


where $R$ is oil resistance in ohm, $\rho$ is the oil resistivity in ohm $\mathrm{cm}, \sigma$ is the oil conductivity in Siemens/cm, $A$ is the electrodes area in $\mathrm{cm}^{2}$ and $d$ is the distance between the electrodes in $\mathrm{cm}$.

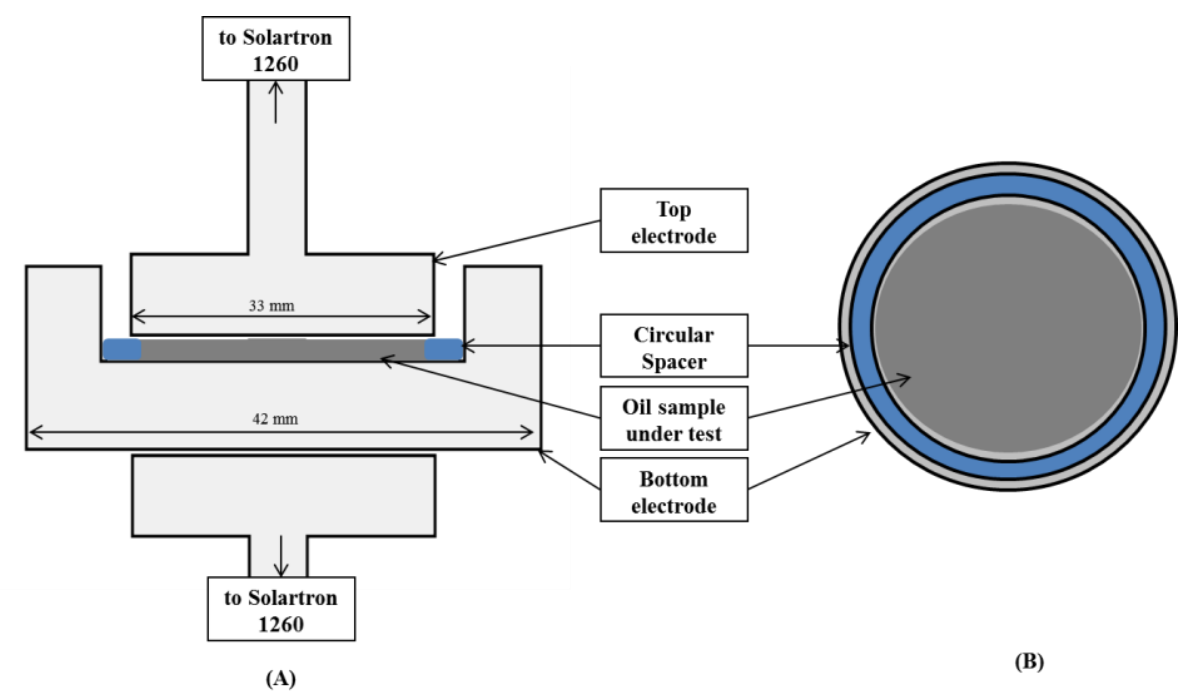

Figure 1: The test cell configuration, (A) side view; (B) top view of the bottom electrode

\subsection{Thick film acidity sensors and oil acidity measurements}

Thick-film screen printing technology consists of the sequential printing and firing of inks onto a substrate. Inks are printed layer by layer on the substrate and each paste serves a specific purpose. The main steps of the fabrication process are printing, drying (at about $150{ }^{\circ} \mathrm{C}$ depending on the paste used) and firing at the specific firing temperature of the ink used ${ }^{24}$.

Thick film (TF) ion selective electrodes (ISE) and TF silver-silver chloride $(\mathrm{Ag} / \mathrm{AgCl})$ reference electrodes were fabricated using the thick film screen printing technique. Reference electrodes should have a stable potential in the test solution while the ion selective electrode (i.e. the working electrode) responds to the change of the $\mathrm{H}+$ concentration in the solution.

The following three different types of TF reference electrodes were fabricated:

a. Silver conductor with an extra layer of glass-based silver-silver chloride $(\mathrm{Ag} / \mathrm{AgCl})$

b. Bare silver conductor

c. Silver conductor with an extra layer of polymer-based $\mathrm{Ag} / \mathrm{AgCl}$

All types of reference electrodes were tested in order to compare their performance and select the most suitable ones for oil acidity measurements. $\mathrm{RuO}_{2}$ working electrode has been shown to have the highest sensitivity to $\mathrm{pH}$ changes compared to any other metal oxide tested in aqueous solutions ${ }^{25,26}$.

The TF electrodes were screen-printed onto $50 \mathrm{~mm}$ x $50 \mathrm{~mm}, 0.625 \mathrm{~mm}$ thick, 96\% alumina substrates (Coorstech). The electrodes were fabricated by successive screen-printing of each separate layer. The screen designs were produced using Autocad 
to give precise dimensions of the mesh openings. Each screen was designed to print a single layer of the electrode. The first type of TF reference electrode was just bare silver conductor. For the $\mathrm{Ag} / \mathrm{AgCl}$ reference electrodes, the first layer printed was the silver conductor with dimensions of $2.25 \mathrm{~mm}$ x $44.55 \mathrm{~mm}$. Secondly, a dielectric layer was deposited on top, to protect the conductor from the electrolyte, leaving a small window opening exposing the underlying silver. The dielectric layer was rectangle of $6.5 \mathrm{~mm} \mathrm{x}$ $43.8 \mathrm{~mm}$. The exposed silver size was $3.4 \mathrm{~mm} \times 3.4 \mathrm{~mm}$ while a part of silver layer approximately $4.15 \mathrm{~mm} \times 2.25 \mathrm{~mm}$ was also exposed at the other end for wire soldering. $\mathrm{A} \mathrm{Ag} / \mathrm{AgCl}$ layer was printed on top of the silver opening as a square of $4 \mathrm{~mm} \times 4 \mathrm{~mm}$, slightly bigger to completely cover it. The inks used for each layer are shown in Table 1. The $\mathrm{TF} \mathrm{Ag} / \mathrm{AgCl}$ reference electrodes mimic the construction of the single junction gel-filled $\mathrm{Ag} / \mathrm{AgCl}$ commercial reference electrode. Two types of $\mathrm{Ag} / \mathrm{AgCl}$ were used, a polymer based ink provided by Gwent Electronic Materials (GEM C61003P7) and a glass based ink provided by Universidad de Politécnica de Valencia in Spain (PPCFB2). For the $\mathrm{RuO}_{2}$ working electrode construction, three different inks were used. The conductor layer was platinum-gold which was screen printed on the same type of substrates, with the same screen as the silver conductor layer. The second layer was a polymer dielectric insulating paste with the same screen as the one used for the dielectric insulator for the reference electrodes. Over the window exposing the conductor, a ruthenium oxide paste was printed as the sensitive material for the $\mathrm{H}+$ concentration. The screen used for this layer was the same as the one used for the $\mathrm{Ag} / \mathrm{AgCl}$ layer of the reference electrodes. The typical construction of a TF working electrode and the TF reference electrodes used in this study are shown in Figure 2. After the printing process for each layer the electrodes were held at room temperature for 10 min to allow relaxation of surface stresses and then dried in an infrared mini-dryer (DEK1209). The layers that required $850{ }^{\circ} \mathrm{C}$ firing were fired in a six zone belt furnace (BTUVQ41) at a peak temperature of $850{ }^{\circ} \mathrm{C}$ with an ascent and decent temperature of $50{ }^{\circ} \mathrm{C} / \mathrm{min}$ keeping it at peak for $10 \mathrm{~min}$. Drying and curing temperatures for each paste are provided in Table 1. Further details of the TF reference and ISE electrodes' construction and fabrication procedure can be found elsewhere ${ }^{22}$.

\begin{tabular}{|c|c|c|c|c|c|}
\hline Layer & Paste & $\begin{array}{c}\text { Drying } \\
\text { temperature }\left({ }^{\circ} \mathrm{C}\right)\end{array}$ & $\begin{array}{c}\text { Drying } \\
\text { time (min) }\end{array}$ & $\begin{array}{c}\text { Curing } \\
\text { temperature }\left({ }^{\circ} \mathrm{C}\right)\end{array}$ & $\begin{array}{c}\text { Curing } \\
\text { time (min) }\end{array}$ \\
\hline $\begin{array}{l}\text { Platinum Gold } \\
\text { Conductor }\end{array}$ & ESL 5837 & 125 & $10-15$ & 850 & $\sim 45$ \\
\hline $\begin{array}{l}\text { Dielectric polymer } \\
\text { insulator }\end{array}$ & $\begin{array}{c}\text { GEM } \\
\text { 2020823D2 }\end{array}$ & - & - & 80 & 30 \\
\hline Ruthenium oxide & C50502D7 & - & - & 80 & $10-15$ \\
\hline Silver conductor & $\begin{array}{c}\text { ESL-9912- } \\
\text { A }\end{array}$ & 125 & $10-15$ & 850 & $\sim 45$ \\
\hline $\begin{array}{l}\text { Dielectric } \\
\text { insulator }\end{array}$ & $\begin{array}{l}\text { ESL-4905- } \\
\text { C }\end{array}$ & 125 & $10-15$ & 850 & $\sim 45$ \\
\hline $\begin{array}{l}\text { Polymer silver - } \\
\text { silver chloride }\end{array}$ & $\begin{array}{c}\text { GEM } \\
\text { C61003P7 }\end{array}$ & - & 10 & 60 & 30 \\
\hline $\begin{array}{l}\text { Glass silver - } \\
\text { silver chloride }\end{array}$ & PPCFB2 & 150 & 10 & 390 & $\sim 30$ \\
\hline
\end{tabular}

Table 1: Drying and curing temperatures for the pastes used for thick film electrodes fabrication 
(a)

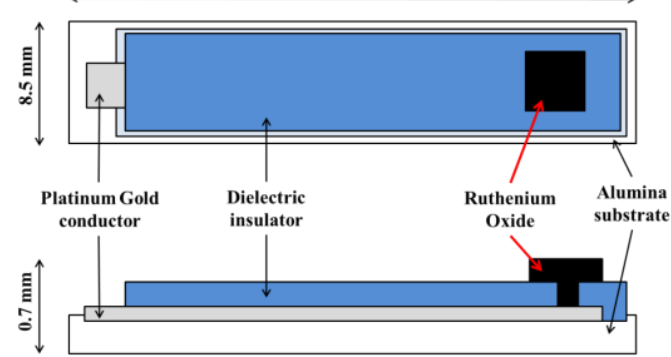

(c)

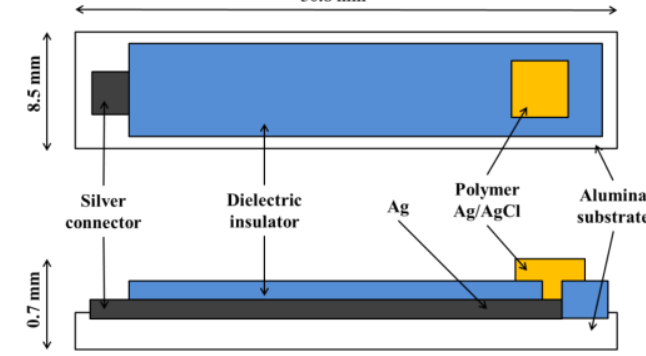

(b)

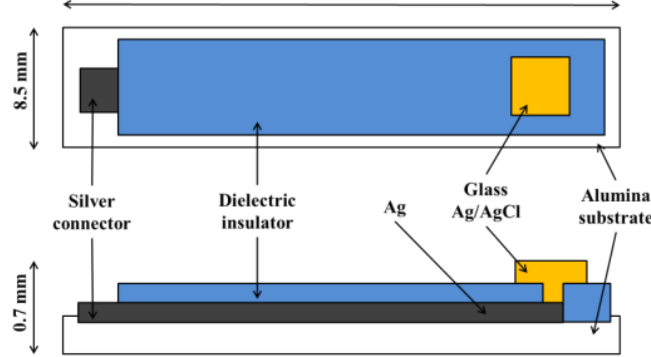

(d)

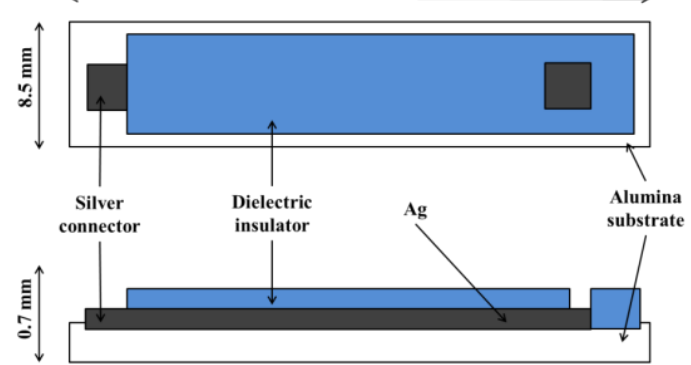

Figure 2: Top-view and cross section of TF, (a) $\mathrm{RuO}_{2} \mathrm{WE}$, (b) glass $\mathrm{Ag} / \mathrm{AgCl} \mathrm{RE}$, (c) polymer Ag/AgCl RE and (d) bare silver RE

As illustrated in Figure 3, one TF ruthenium oxide $\mathrm{pH}$ electrode was used as the working electrode (WE) against three types of TF reference electrodes (RE) as well as a commercial reference electrode connected to a high input impedance ( tera-ohm) voltmeter (Metrohm $827 \mathrm{pH} \mathrm{lab).} \mathrm{The} \mathrm{commercial} \mathrm{glass} \mathrm{gel-filled} \mathrm{Ag} / \mathrm{AgCl}$ reference electrode (A57193 from Beckman Coulter) was used as a comparison to the TF reference electrodes. During testing, all electrodes (WE and RE) were initially hydrated and tested in aqueous buffer solutions to ensure their performance was acceptable. The electrodes were then tested in the oil samples at two temperatures $\left(50\right.$ and $\left.80{ }^{\circ} \mathrm{C}\right)$ in a thermostatically controlled water-bath. These temperatures were chosen to represent engine operating temperatures within the oil sump ${ }^{27}$.

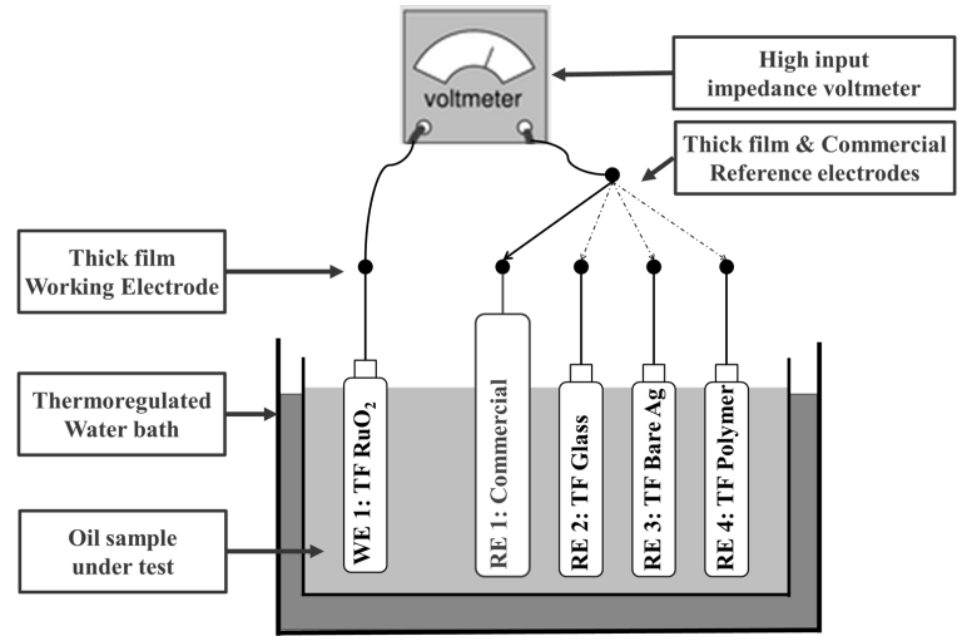

Figure 3: Oil acidity measurement setup using Thick Film electrodes 


\section{Results and Discussions}

The details of the oxidised oil samples, AN, water content and viscosity measurements at two temperatures are shown in Table 2.

\begin{tabular}{|c|c|c|c|c|c|}
\hline $\begin{array}{c}\text { Oil } \\
\text { samples }\end{array}$ & $\begin{array}{c}\text { Oxidation } \\
\text { (hours) }\end{array}$ & $\begin{array}{c}\text { Acid number } \\
(\mathbf{m g K O H} / \mathbf{g})\end{array}$ & $\begin{array}{c}\text { Viscosity at } \\
\mathbf{5 0}^{\circ} \mathbf{C}(\mathbf{m P a . s})\end{array}$ & $\begin{array}{c}\text { Viscosity at } \\
\mathbf{8 0}^{\circ} \mathbf{C}(\mathbf{m P a . s})\end{array}$ & $\begin{array}{c}\text { Water content } \\
(\boldsymbol{\mu g} / \mathbf{m l})\end{array}$ \\
\hline $\mathbf{1}$ & Fresh oil & 0 & 25 & 10 & 7.8 \\
\hline $\mathbf{2}$ & 2 & 1.7 & 30.6 & 12.5 & 330.1 \\
\hline $\mathbf{3}$ & 4 & 4.7 & 37.5 & 15 & 541.5 \\
\hline $\mathbf{4}$ & 8 & 12.5 & 52.5 & 19 & 1819.1 \\
\hline $\mathbf{5}$ & 16 & 28 & 80 & 27 & 2495.0 \\
\hline $\mathbf{6}$ & 20 & 29 & 120 & 36.2 & 1736.8 \\
\hline $\mathbf{7}$ & 24 & 32 & 166.8 & 49.3 & 1328.0 \\
\hline
\end{tabular}

Table 2: Details of the oxidised oil samples

\subsection{Electrochemical Impedance Spectroscopy (EIS):}

The EIS results are presented in two forms, namely Bode and Nyquist plots. Figures 3 and 4 are the Bode plot representation of the oxidised oil samples impedance at 50 and $80{ }^{\circ} \mathrm{C}$. Figures $3 \mathrm{a}$ and $4 \mathrm{a}$ show the impedance magnitude of each oil sample as a function of frequency (on logarithmic scales) and Figures $3 \mathrm{~b}$ and $4 \mathrm{~b}$ show the corresponding phase angle data. In each case, results obtained from different samples are presented using different colours (e.g. green for fresh oil and red for the oil aged for 24 hours). The impedance magnitude of the fresh oil displays an inverse dependence on frequency and the phase angle between the voltage and current is close to $-90^{\circ}$, indicating that, as expected, the characteristics of the system are dominated by capacitive effects. The behaviour of 2 hours (dark grey line) oxidised oil sample is very similar to that of fresh oil, apart from the phase angle at lower frequencies (1 Hertz) which goes up to $-65^{\circ}$ at $80{ }^{\circ} \mathrm{C}$. For more highly oxidised oil samples at lower frequencies down to $1 \mathrm{~Hz}$ (which for all practical purposes can be considered as DC) the impedance is constant with frequency and the phase angle is close to zero indicating predominantly resistive behaviour. For instance the resistive behaviour of the 8 hours oxidised oil sample starts are around $10 \mathrm{~Hz}$ in comparison to $100 \mathrm{~Hz}$ for the 20 and 24 hours oxidised oil samples. Therefore, the higher the oxidation of the oil samples, the lower is the impedance and their system behaves more like a resistor. The $80{ }^{\circ} \mathrm{C}$ graphs are quite similar to those for $50{ }^{\circ} \mathrm{C}$; however, the overall level of impedance is lower. Figure 6 illustrates the capacitance magnitude of the oxidised oil samples as a function of frequency and, as can be seen, the capacitance increases at low frequencies for higher oxidised oil samples.

Please note that the lines included in the figures to connect the data points together only serve to guide the eyes. 
(a)

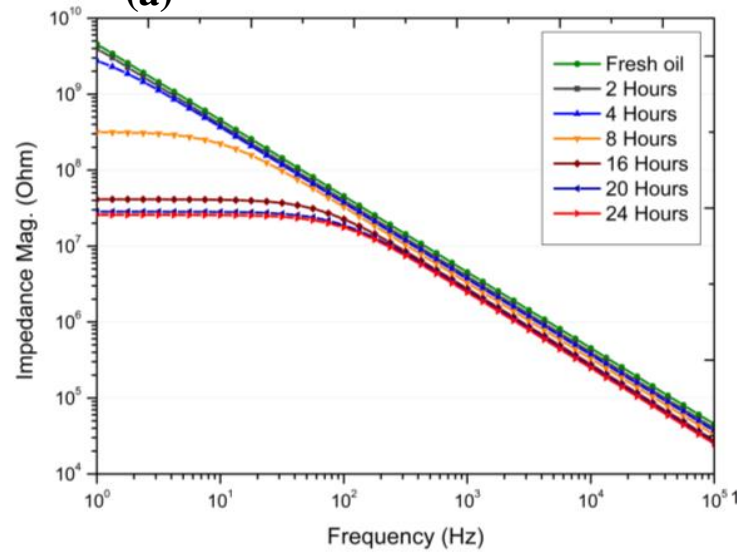

(b)

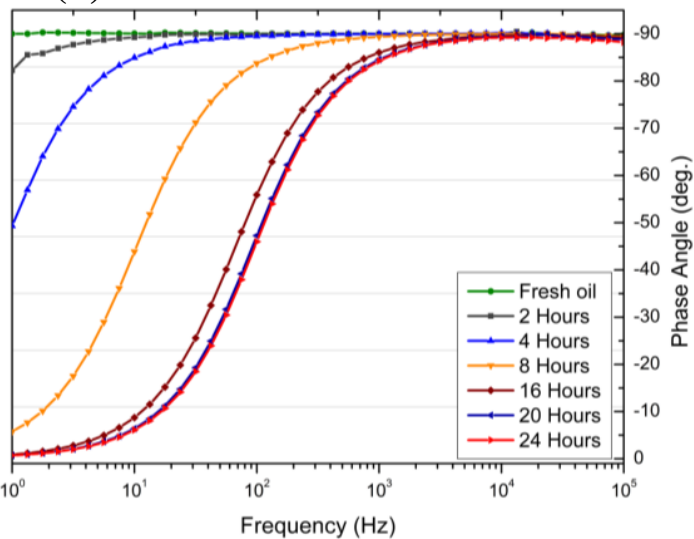

Figure 4: Bode plot of the oxidised oil samples at $50{ }^{\circ} \mathrm{C}$

(a)

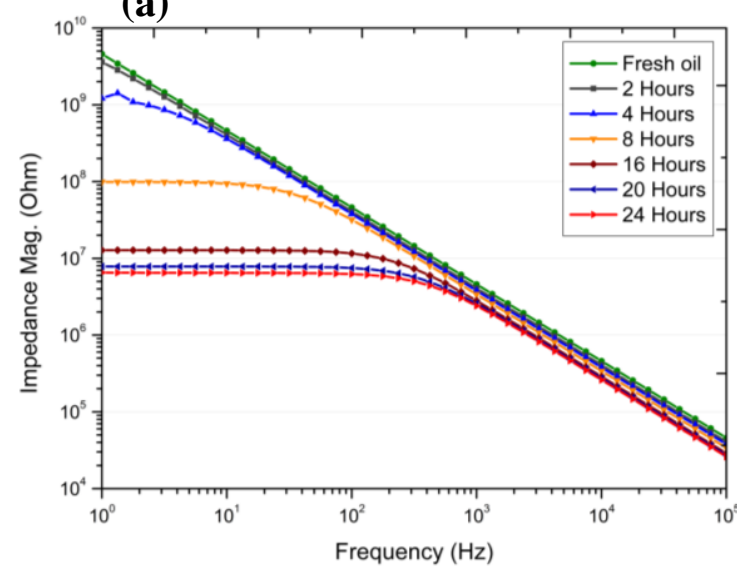

(b)

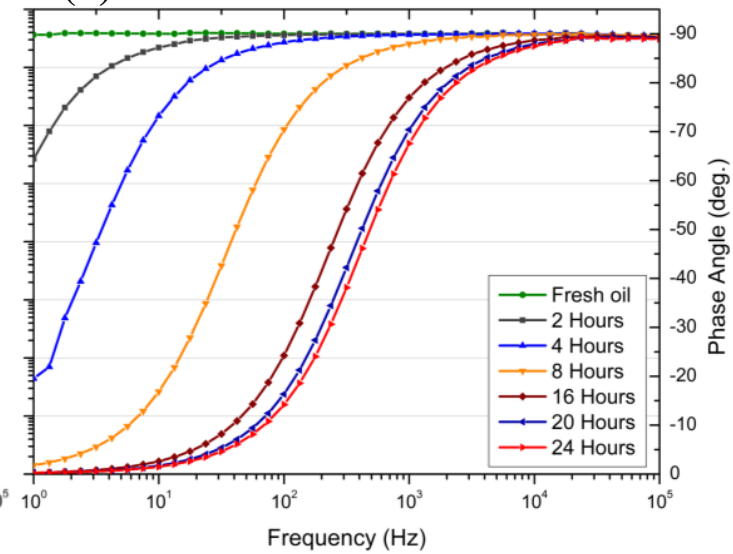

Figure 5: Bode plot of the oxidised oil samples at $80{ }^{\circ} \mathrm{C}$

(a)

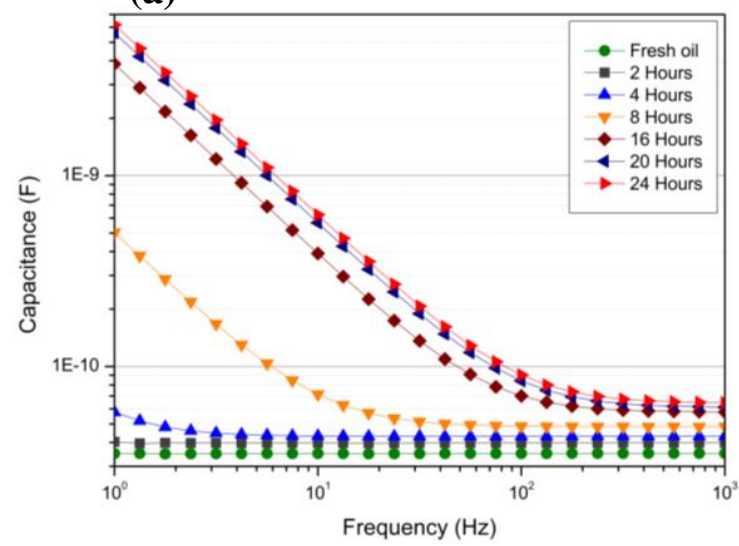

(b)

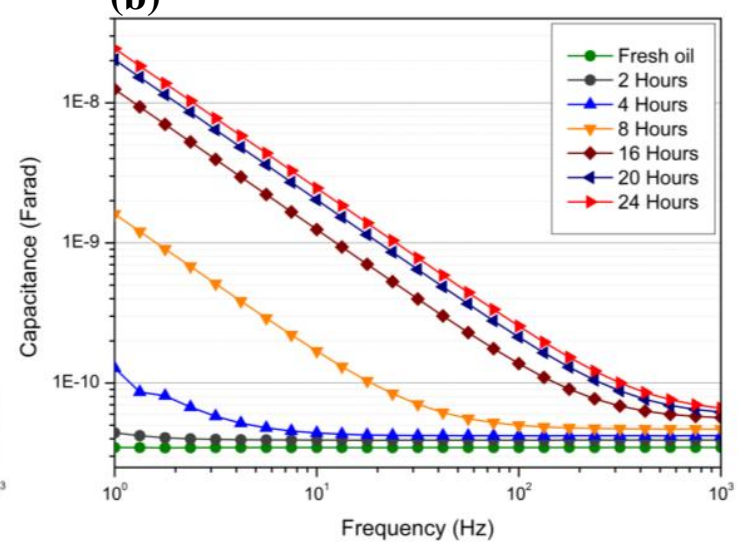

Figure 6: Capacitance magnitude of the oxidised oil samples $(1-1000 \mathrm{~Hz})$ at: a) $50{ }^{\circ} \mathrm{C}$ and b) $80{ }^{\circ} \mathrm{C}$

The real (on the x-axis) and imaginary (on the y-axis) parts of the impedance of the oxidised oil samples are plotted in Figure 7 and Figure 8 as Nyquist plots or complex plane impedance diagrams at 50 and $80{ }^{\circ} \mathrm{C}$ respectively. Each point on the plot (i.e. impedance at different frequencies) is also representative of the impedance as a vector of length $(|\mathrm{Z}|)$ and phase angle $(\phi)$. As can be seen, semicircles are formed (except for fresh and 2 hours oxidised oil samples) and as the oxidation hours increase, 
the circles become smaller due to reduced impedance (the diameter of the semicircle corresponds to the resistance R). As seen in the more highly oxidised oil samples (i.e. 8, 16, 20 and 24 hours oxidised oil samples), perfect semicircles represent the impedance response corresponding to a single charge-transfer process and resistive behaviour of the oil samples. Fresh and 2 hours oxidised oils show significant capacitive impedance (very large semicircles) indicating a very high impedance to the passing current and capacitive behaviour. As expected, the radius of the semicircles reduces at higher temperatures due to decreased impedance. A minor glitch is observed in the impedance data of the 4 hours oxidised oil sample in Figure 8.
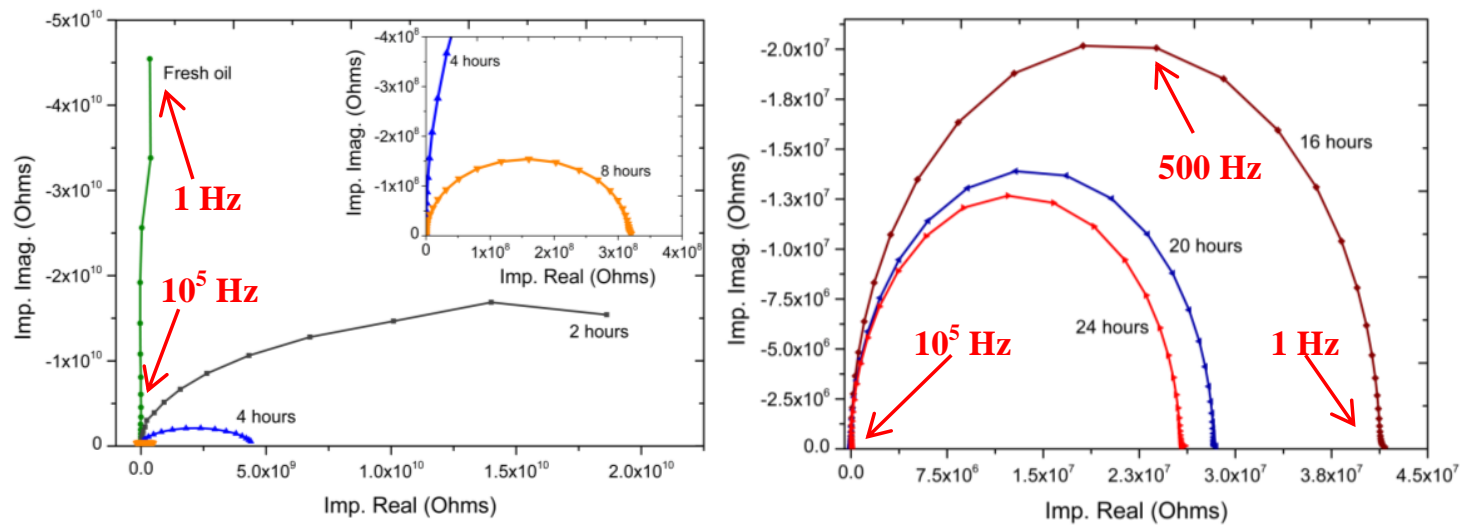

Figure 7: Nyquist plots of the oxidised oil samples at $50{ }^{\circ} \mathrm{C}$
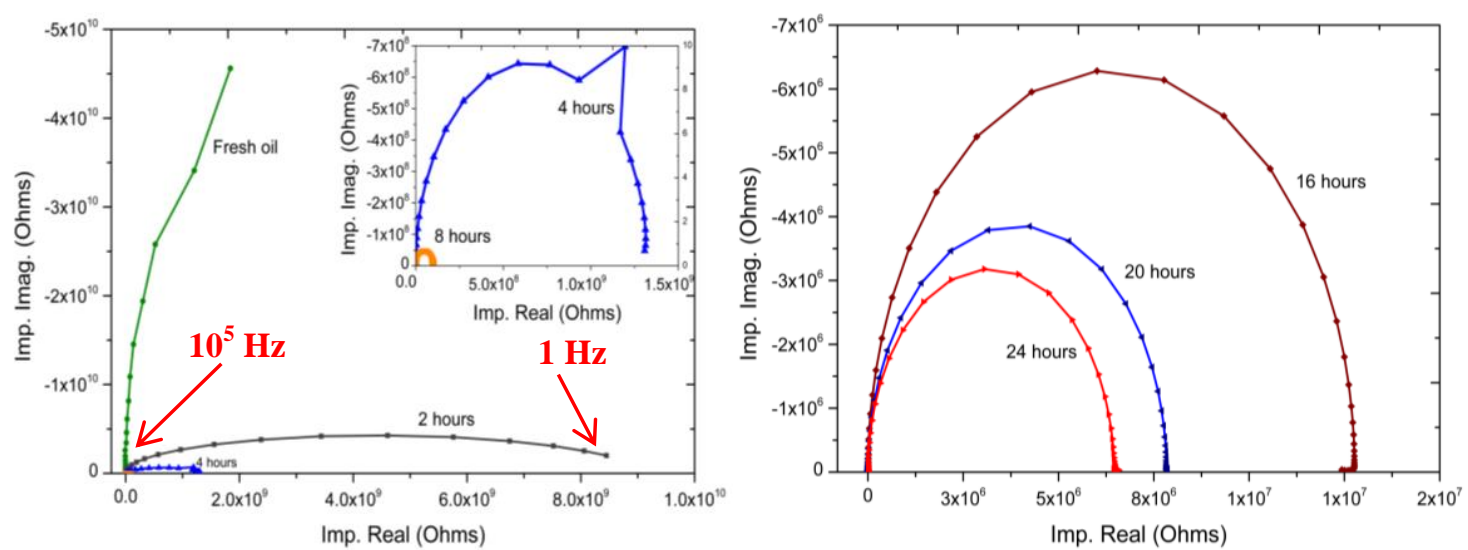

Figure 8: Nyquist plots of the oxidised oil samples at $80^{\circ} \mathrm{C}$

The effective conductivity was calculated from the impedance in the $D C$ regime (or frequency independent $\mathrm{Z}$ ), i.e. the impedance at low frequency $(1 \mathrm{~Hz})$ which represents the bulk resistance of the oil sample. Figure 9 depicts the effective conductivity plots of the oxidised oil samples at 50 and $80{ }^{\circ} \mathrm{C}$ and indicates that the oil conductivity increases with oil oxidation time. It is noteworthy that the rate of conductivity increase at lower oxidation times (i.e. over the first three oil samples) is much lower than that for the more highly oxidised oil samples (last four oil samples), probably as a consequence of fast radical chain propagation after 4 hours of oxidation. The slow increase in the conductivity of the oil samples between 0 to 4 hours can be an indication of the first phase of oil oxidation process, i.e. slow radical chain reaction at the oxidation initiation stage. 
The conductivity of the oil samples at $80{ }^{\circ} \mathrm{C}$ is higher than that at $50{ }^{\circ} \mathrm{C}$ which may be a result of the lower oil viscosity and higher ion mobility at the higher temperature.

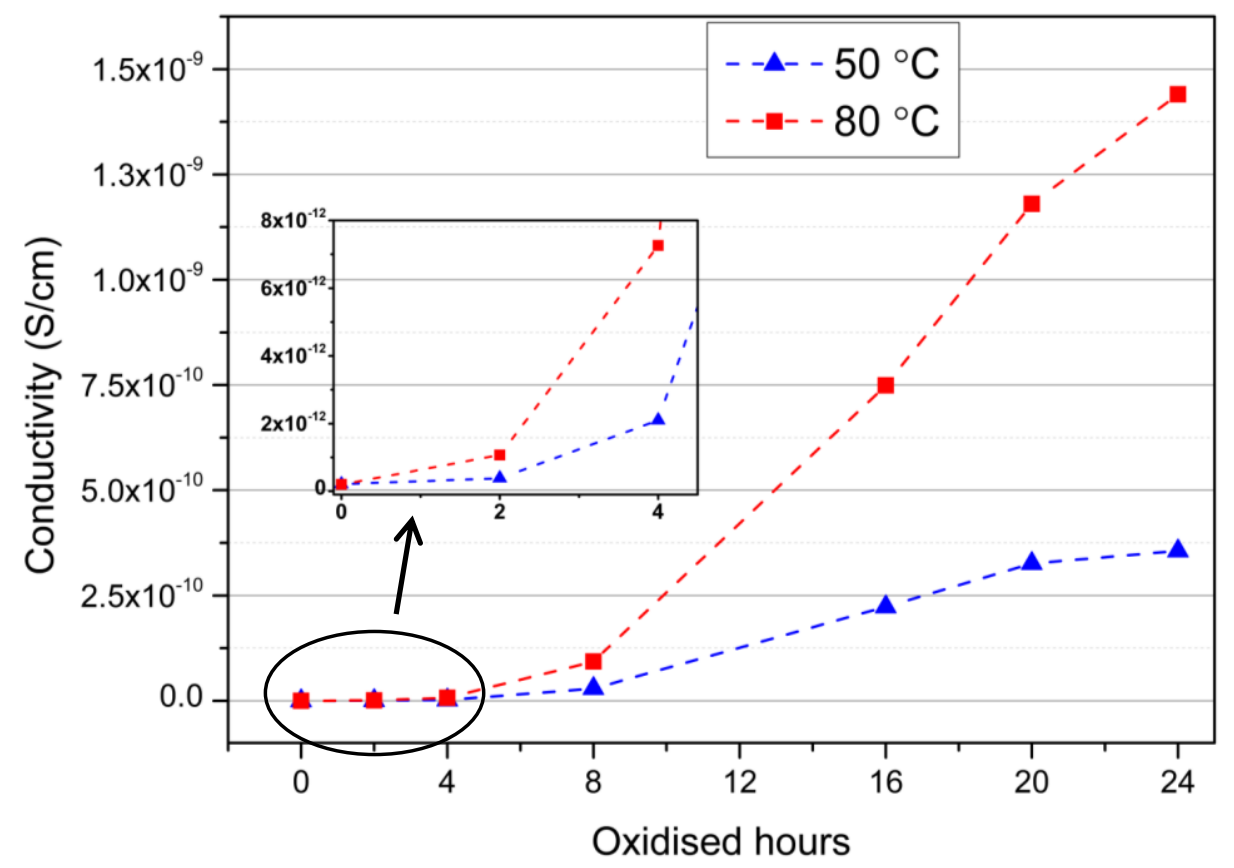

Figure 9: Effective conductivity of the oxidised oil samples at 50 and $80{ }^{\circ} \mathrm{C}$

\subsection{Measurements using TF sensors}

Figure 10 illustrates the responses of the electrodes (4 WE-RE pairs) in the various oil samples at $50{ }^{\circ} \mathrm{C}$ and $80{ }^{\circ} \mathrm{C}$. The performance of the 4 electrode pairs at 50 ${ }^{\circ} \mathrm{C}$ and $80{ }^{\circ} \mathrm{C}$ was, surprisingly, very similar, especially for the bare silver RE when compared to both of the solid state $\mathrm{Ag} / \mathrm{AgCl} \mathrm{RE}$ 's and the commercial liquid electrolyte $\mathrm{RE}$. This is probably due to the fact that any changes in the potential of the reference electrodes are insignificant compared to the change in potential of the working electrode. The consistency in the potential of the bare silver RE was unexpected in comparison to $\mathrm{Ag} / \mathrm{AgCl} \mathrm{REs}$ and the results suggest that the bare silver does not react with the chemical species in the oil. Therefore, it acts as a simple conductor with a stable voltage similar to the other REs. The negative polarity from the electrodes indicates that the working electrode had a lower potential than the reference electrodes. At $50{ }^{\circ} \mathrm{C}$, the output voltage of the TF sensors increased with oxidation time up to 20 hours and plateaued up to the 24 hours oxidised oil at approximately 0 volts. This plateau is observed sooner at $80{ }^{\circ} \mathrm{C}$ from 16 hours onward at which point the output voltage also reached approximately 0 volts. Zero volt potential suggests the presence of a short circuit by sensor malfunction probably caused by the extremely high acidity of the oil samples. The AN of 29 and $32 \mathrm{mgKOH} / \mathrm{g}$ for 20 and 24 hours oxidised oil samples are extremely high compared to maximum AN value of $6 \mathrm{mgKOH} / \mathrm{g}$ in turbine, gear and hydraulic oils ${ }^{28}$. The ruthenium oxide working electrode is probably being stripped/ reduced by the high acidity of the solution, enhanced by the elevated temperature which could potentially leave ruthenium metal (no oxide) or even the bare metal of the back contact (platinum/gold) on the substrate. In any case, this could then 
leave just a purely conductive electrode pair with no $\mathrm{H}^{+}$response. When that happens, the sensor tends to short circuit as there are two conductors in the same oil having very similar electrode potentials. At this point, oil conductivity has increased significantly responding as an electrical component which results in an almost zero potential. This phenomenon was further investigated by comparing the SEM (scanning electron microscope) and EDX (energy-dispersive X-ray) analysis of the surface and cross section of the fresh (before testing in oxidised oil samples) and used (after testing) ruthenium oxide working electrode. Figure 11a illustrates the uniform surface of the fresh electrode and the SEM results of the used electrode (Figure 11b) shows the damage to the top layer of the TF working electrode. EDX analysis of the fresh electrode shows that there is a uniform layer of ruthenium oxide on the top layer of the WE. Alternatively, the EDX analysis of the used electrode (tables for the points A and $\mathrm{B}$ below the Figure 11b) shows the removal of the top layer, on certain parts of the electrode, as evidenced by the presence of substances from the bottom layer (platinum/gold). The small amount of palladium substance observed in the bottom layer, is used extensively in platinum/gold pastes by the manufacturer, to increase the solderability of the conductor. The carbon on the surface of the used electrode might be from the oxidised oil samples.

The maximum rate of change of acidity occurs between 2 and 16 hours at $50{ }^{\circ} \mathrm{C}$, while at $80{ }^{\circ} \mathrm{C}$ it occurs between 0 and 16 hours. The rate of most reactions is highly dependent on temperature. As the temperature increases, the rate of the reaction increases. The reduction of ruthenium oxide to ruthenium metal, destroying the sensors, occurs earlier at $80{ }^{\circ} \mathrm{C}$ than at $50{ }^{\circ} \mathrm{C}$ for the same exact reasons.
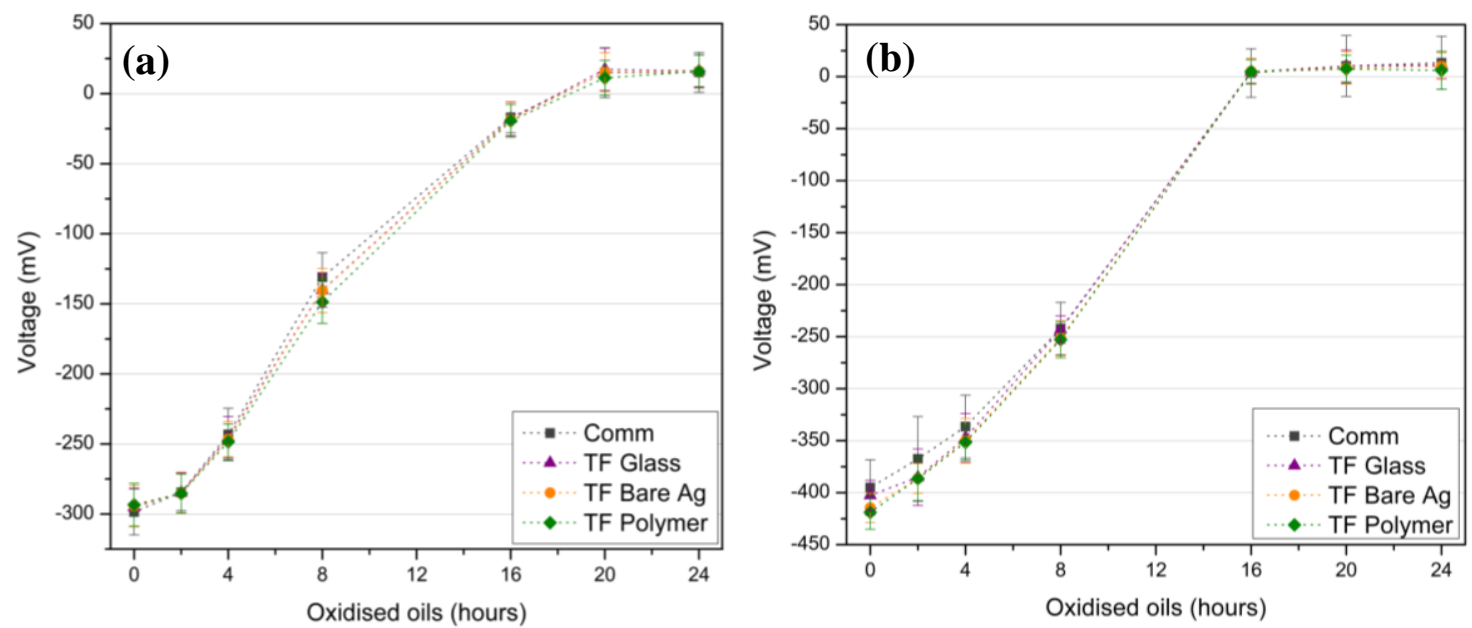

Figure 10: TF sensors output in oxidised oil samples, a) at $50{ }^{\circ} \mathrm{C}$ and b) at $80{ }^{\circ} \mathrm{C}$ 
(a)

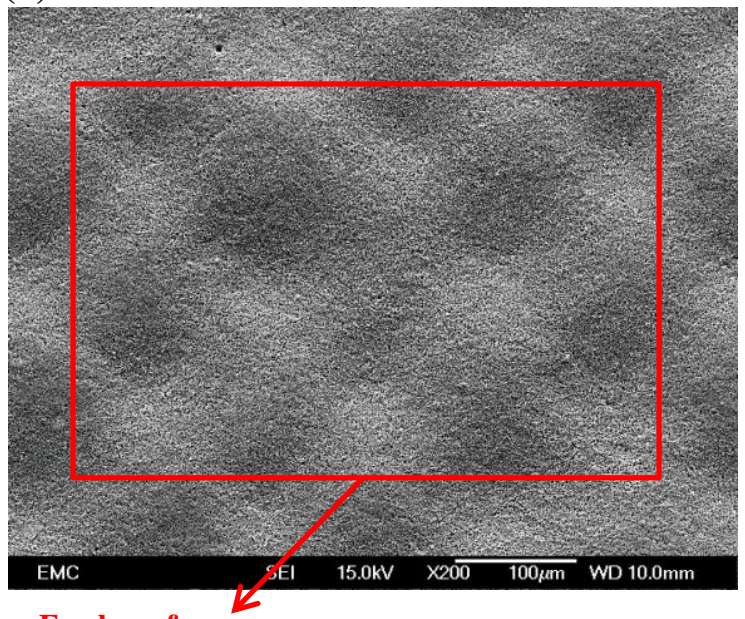

Fresh surface area:

\begin{tabular}{|c|c|}
\hline Element & Weight\% \\
\hline $\mathrm{O}$ & 28.15 \\
\hline $\mathrm{Ru}$ & 71.85 \\
\hline Totals & 100.00 \\
\hline
\end{tabular}

(b)

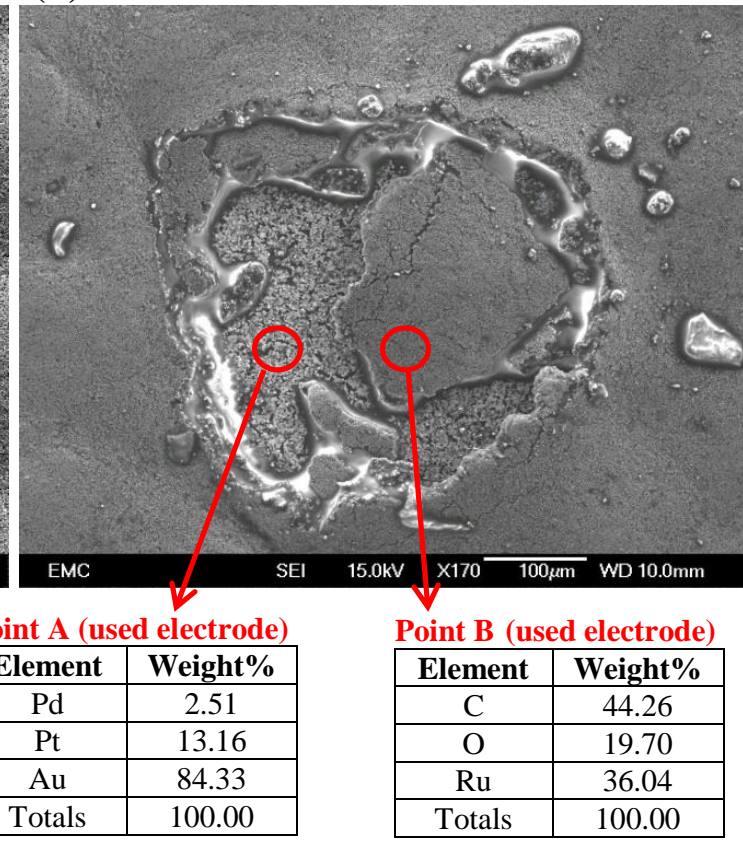

Figure 11: SEM results and the EDX analysis (shown in the tables below the figures) from fresh and used TF $\mathrm{RuO}_{2}$ working electrodes, (a) surface of the fresh electrode (wavy feature seen on the fresh electrode surface is due to the printing process (i.e. steel screen and heating effect), (b) surface of the used electrode

\subsection{TF sensors vs. AN, viscosity, conductivity \& water content}

The AN of the oil samples at room temperature increased with oxidation time as shown in Figures 9 and 10. It can be seen that the oxidation process has produced significant amounts of acidic compounds, such as carboxylic acids, in the oil even at very low oxidation time i.e. 2 and 4 hours. This is because without additives, such as anti-oxidants, to prevent the acidity increase by neutralising the formed acidic compounds, the base oil can be oxidised easily. Different phases of the oxidation process can be observed in the AN graph, where the slow increase in oil acidity between 0 and 4 hours represents the oxidation initiation stage, followed by a rapid increase in oil acidity between 4 and 16 hours (propagation, chain branching and auto-oxidation period) leading to termination phase in which cross-linking considerably increases oil viscosity between 16 and 24 hours where a slow increase in AN is seen. This is also reflected in the viscosity changes.

The rate of increase in oil acidity is much higher at low oxidation hours ( 0 to 28 $\mathrm{mgKOH} / \mathrm{g}$ for $0-16$ hours of oxidation) compared to high oxidation times (28 to 32 $\mathrm{mgKOH} / \mathrm{g}$ for 16-24 hours of oxidation). This is probably because the oxidation process has entered its final phase, i.e. termination phase in which the carbons are consumed/oxidised, i.e. hydrogen bonded to carbons are replaced by oxygen, producing $\mathrm{CO}_{2}$ and $\mathrm{H}_{2} \mathrm{O}$ and various other products such as carboxylic acid ${ }^{1,2}$.

Figure 14 shows the output of the TF electrodes versus acid number at two temperatures. As can be seen, all of the TF electrodes responded to oil acidity changes in a linear fashion $\left(R^{2}\right.$ value of $>0.98$ for all electrode pairs) with low errors $(\sim 2 \%)$. This demonstrated that the sensor can be used to detect the oil acidity and oxidation at the temperatures tested. This relationship does not occur for the output of the TF electrodes 
versus viscosity and conductivity (Figures 12 and 13 respectively) although both viscosity and conductivity increase. This indicates that the sensors are highly sensitive to oil AN and not viscosity and conductivity.

The viscosity of the oxidised oil samples initially increased gradually from 25 to $80 \mathrm{mPa}$.s for the 0 to 16 hours oil samples but more significantly at higher oxidised times (from 80 to $166.8 \mathrm{mPa}$.s for 16 to 24 hours oxidised oils). This is probably due to the association of organic acids such as carboxylic acids in oil as carboxylic acid compounds being highly attractive causing them to behave as a larger molecule which increase the oil density of the molecules resulting in considerable viscosity increase at higher oxidation hours ${ }^{1,2}$. The output of TF electrodes versus viscosity at $50{ }^{\circ} \mathrm{C}$ and 80 ${ }^{\circ} \mathrm{C}$ is shown in Figure 15. There seems to be no relationship between the TF sensors output and oil viscosity and the performance of the sensors is independent of viscosity.

The conductivity of the oil samples increased with the level of oxidation, similar to that of the viscosity and AN. The output of TF electrodes versus conductivity at 50 ${ }^{\circ} \mathrm{C}$ and $80{ }^{\circ} \mathrm{C}$ is shown in Figure 16. Oil conductivity is dependent on many factors such as temperature. It can also be influenced by two parameters: directly proportional to ion concentration and inversely dependant on viscosity which itself affects the ionic mobility in the oil sample and depends on temperature. The increase in oil ion concentration as a result of oxidation is more dominant than the inverse viscosity effect, hence the conductivity continues to increase even at high viscosities at both temperatures.

As can be seen in Figure 15 and Figure 16, TF sensors output vs. viscosity and conductivity have similar shape as TF sensors output vs. oxidised oils (in hours) which suggests that the performance of the TF electrodes is independent of viscosity or conductivity. Conductivity only becomes a major factor when ruthenium oxide is reduced to ruthenium and acts as a simple metal conductor in the case of the most highly oxidised oil samples. In these oil samples, instead of oil acidity measurement, the potential difference between the two electrodes (two metal conductors due to extreme AN) in oil is measured. The oil has a very high conductivity at this point and, therefore, the potential difference recorded is extremely low (almost zero).

Figure 17 illustrates the response of TF electrodes $\left(\mathrm{TF} \mathrm{RuO}_{2} \mathrm{WE}\right.$ vs. Polymer RE, Polymer RE was selected randomly to represent the output of the TF electrodes) at two temperatures (i.e. $50^{\circ} \mathrm{C}$ and $80{ }^{\circ} \mathrm{C}$ ) together with the water content measurement of the oxidised oil samples at room temperature. As can be seen, the water content of the oxidised oil samples increase with the oxidation hours for the first five oil samples and decrease considerably for the last two oil samples. Water is a by-product of oil oxidation; hence, as expected, the water content rises as oxidation progresses. The decline in the water content of the last two oil samples may be caused by solubility issues as a result of excessive oil viscosity, i.e. the oil is not fully dissolving within the timescale allowed for the testing. As discussed, the TF electrodes demonstrated a linear correlation with oil acidity (AN) and water content increase may have accelerated the disassociation of acid in oil. This effect might have improved the performance of the TF electrodes in detecting the $\mathrm{H}+$ concentration in the oil samples. This phenomenon can be further explored to observe the exact effect of water on the TF electrodes. 


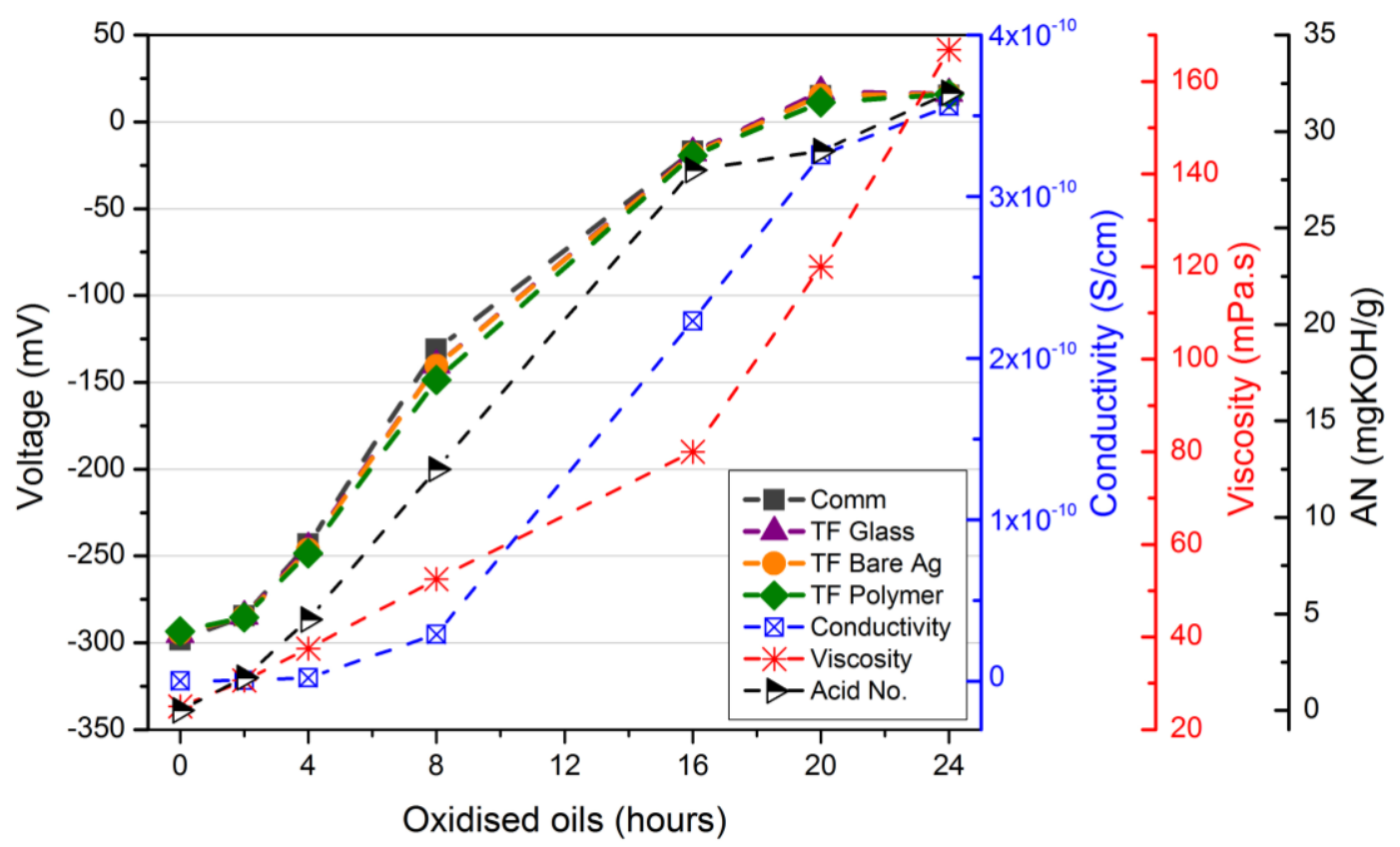

Figure 12: Thick-film electrodes output alongside AN, viscosity and conductivity graphs at $50{ }^{\circ} \mathrm{C}$

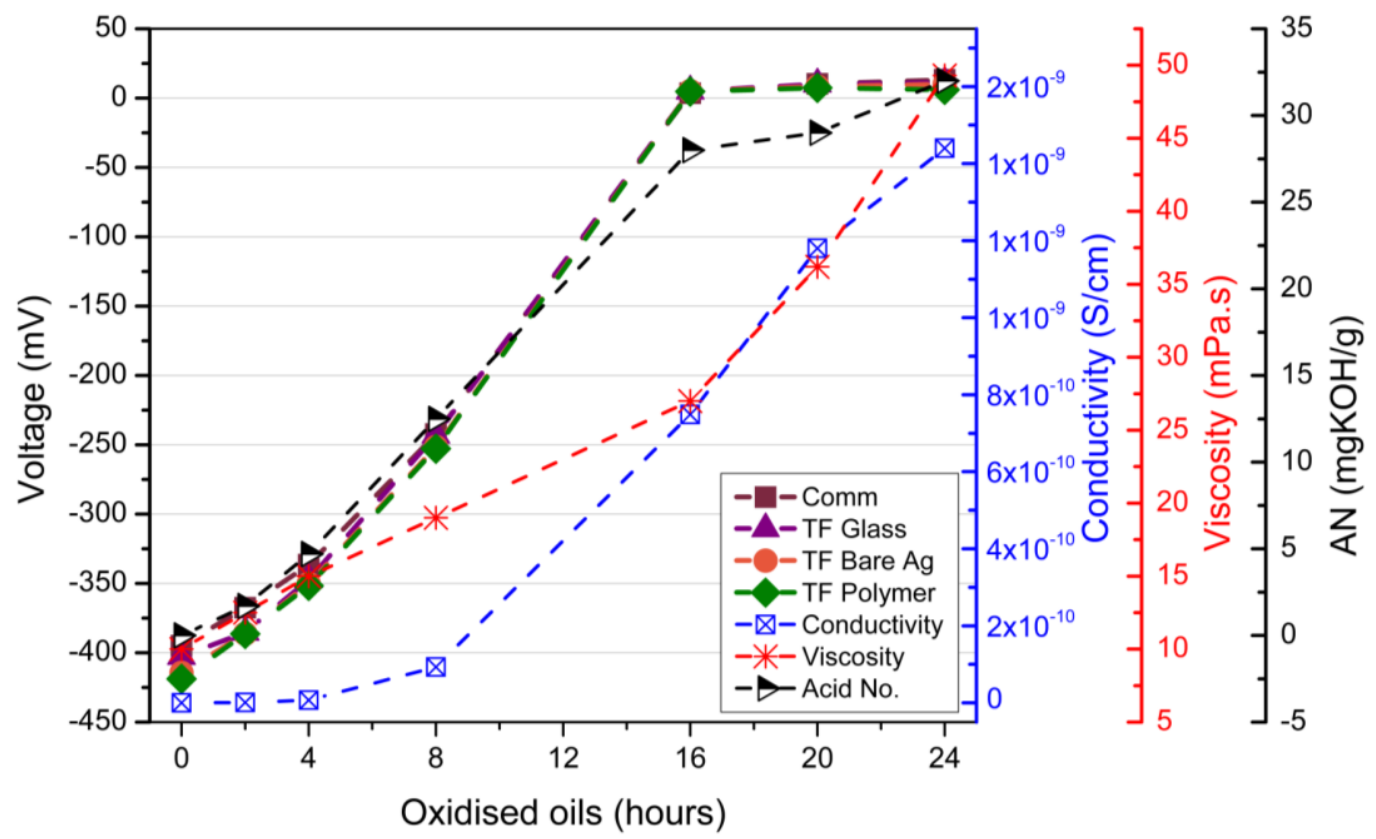

Figure 13: Thick-film electrodes output alongside AN, viscosity and conductivity graphs at $80{ }^{\circ} \mathrm{C}$ 

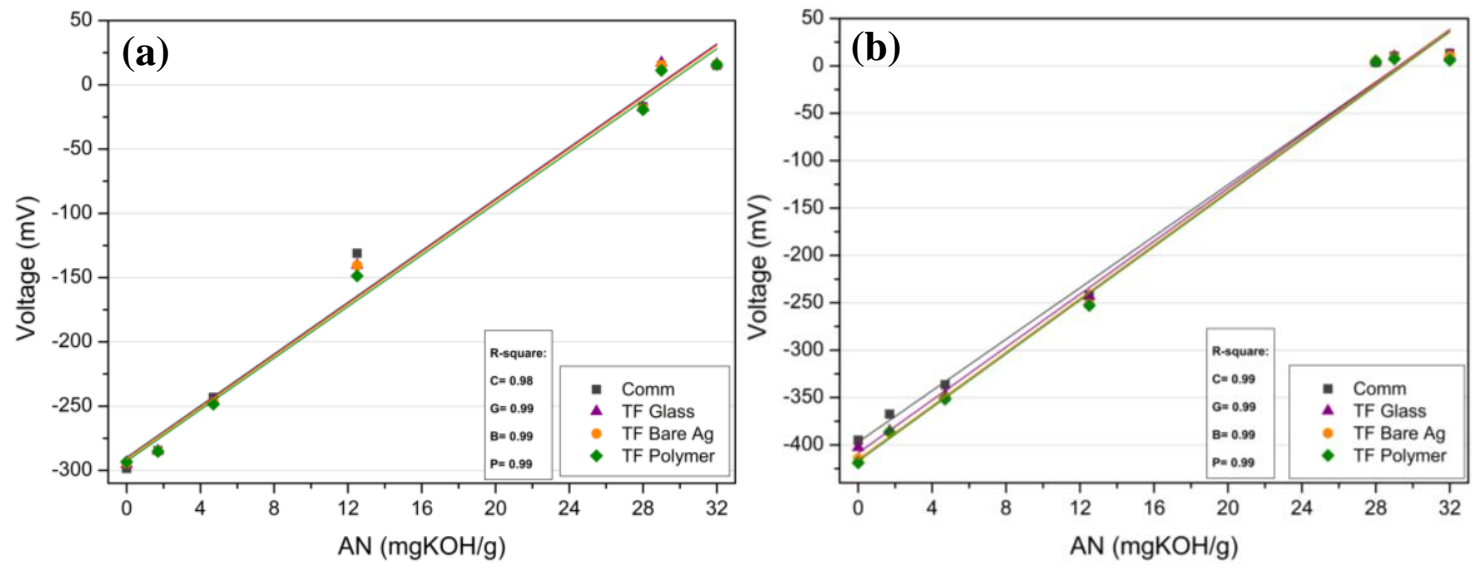

Figure 14: TF vs. AN of the oxidised oil samples, a) at $50{ }^{\circ} \mathrm{C}$ and b) at $80{ }^{\circ} \mathrm{C}$
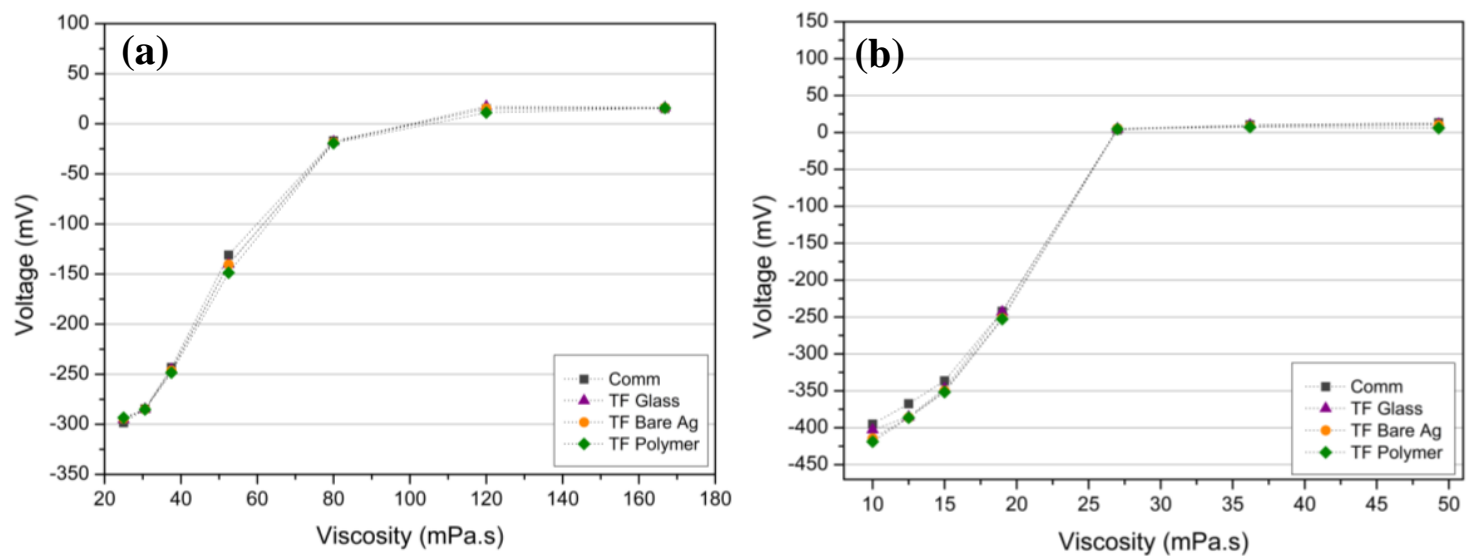

Figure 15: TF vs. viscosity of the oxidised oil samples, a) at $50{ }^{\circ} \mathrm{C}$ and b) at $80{ }^{\circ} \mathrm{C}$
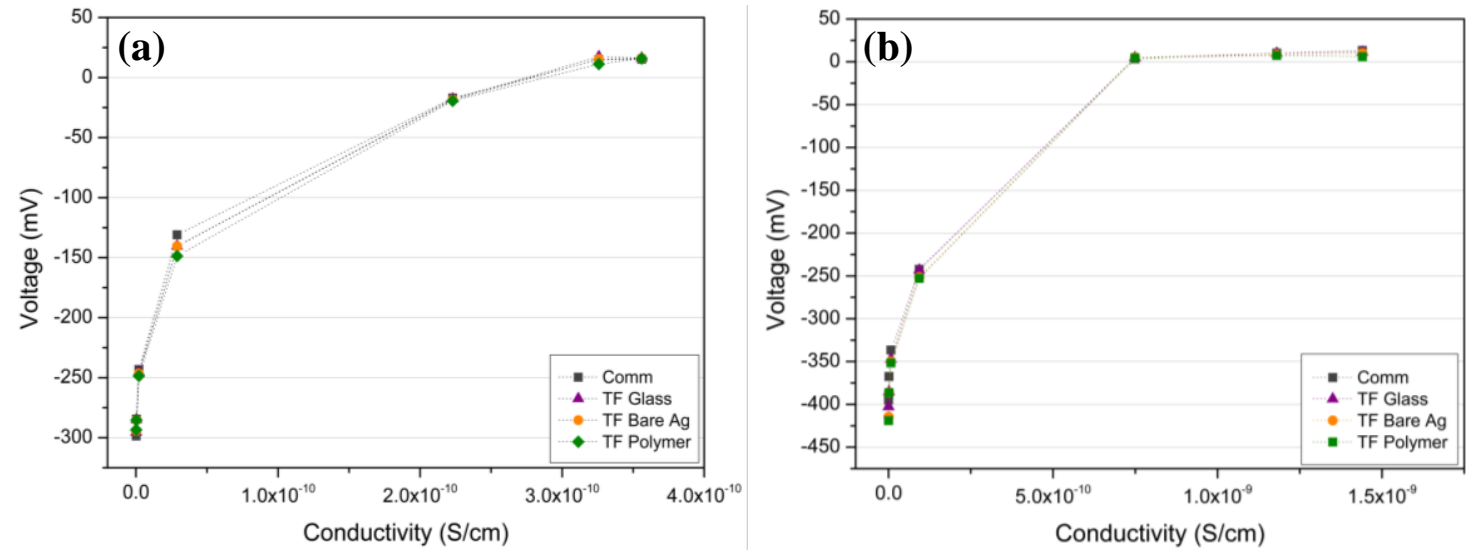

Figure 16: TF vs. conductivity of the oxidised oil samples, a) at $50{ }^{\circ} \mathrm{C}$ and b) at $80{ }^{\circ} \mathrm{C}$ 


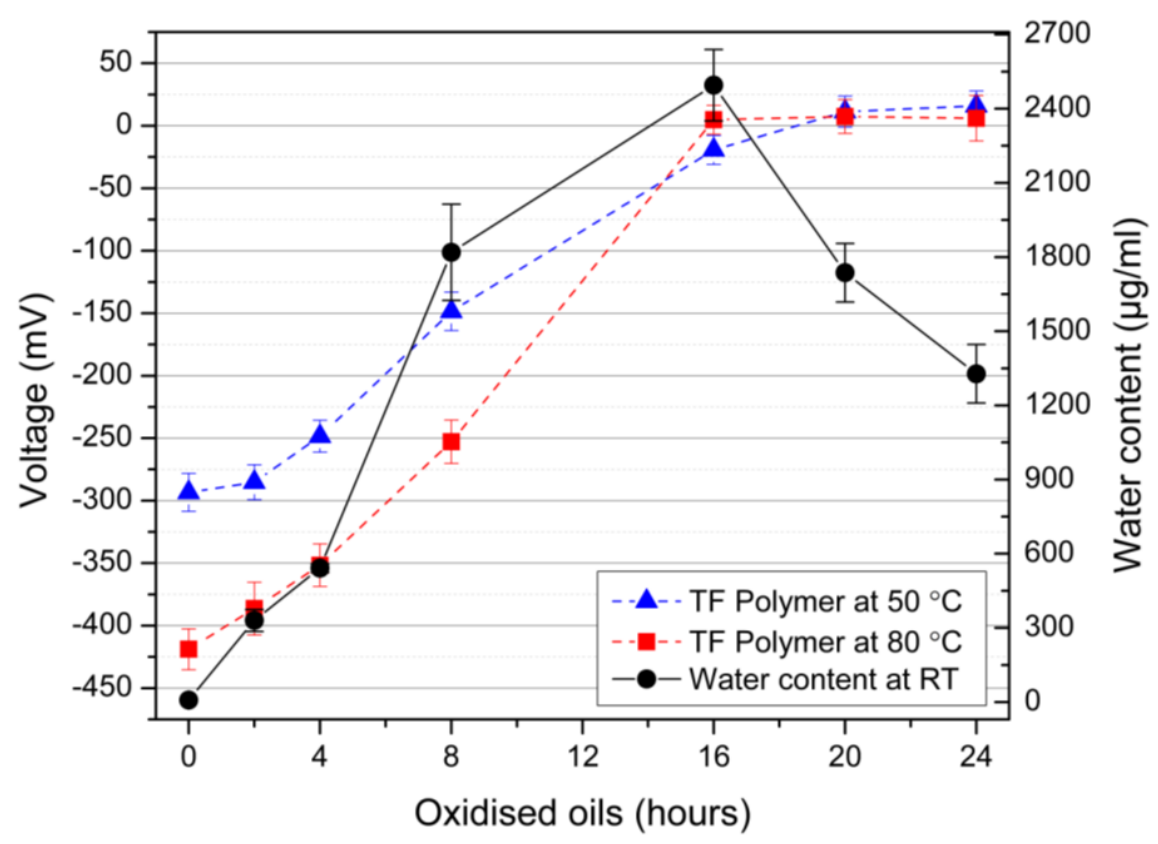

Figure 17: $\mathrm{TF} \mathrm{RuO}_{2} \mathrm{WE}$ vs. Polymer RE at $50{ }^{\circ} \mathrm{C}$ and $80^{\circ} \mathrm{C}$ (left hand-side Y-axis) alongside water content plot (right hand-side Y-axis) of the oxidised oil samples (measured at room temperature (RT)) 


\section{Conclusions}

Oxidised base oil samples, produced under controlled conditions, were used to evaluate the performance of the novel TF acidity sensors. Other properties including oil acid number (AN), viscosity and conductivity were measured for comparison. The main conclusions are:

- The EIS results have demonstrated that this is a viable technique to measure oil conductivity. As the oil oxidation time increases, the conductivity of oil samples also increased. The rate of increase of the oil conductivity could be a reflection of different oil oxidation stages.

- The novel TF sensors detected the oil oxidation and acidity increase. The TF sensors detect the acidity increase in base oil linearly at both 50 and $80{ }^{\circ} \mathrm{C}$ with low errors.

- Sensor working range: it was found that the sensors perform well in overly oxidised oil samples giving a linear response within the approximate AN range of zero to 25 $\mathrm{mgKOH} / \mathrm{g}$.

- Temperature has an influence on the lifetime and usable range of the sensors as the output was reduced at higher temperatures, most probably due to accelerated failure of the ruthenium oxide layer.

Further studies with oxidised fully formulated engine oil have been carried out and the results will follow. The results suggest that on-line oil acidity measurement as an important factor of oil quality monitoring could be performed in combustion engines augmenting conventional oil condition monitoring methods (e.g. oil level and pressure monitoring).

\section{Acknowledgements}

The authors would like to thank Shell Global Solutions (UK) for funding this project and Mr Brian Papke from Shell Technology Centre (Houston, US) for preparing the oxidised oil samples. 


\section{References}

${ }^{1}$ R M Mortier, M F Fox, S T Orszulik, 'Chemistry and Technology of Lubricants', Springer, UK, 2010.

${ }^{2}$ R Wurzbach, 'Lubricant Oxidation Analysis and Control', Practicing Oil Analysis, Machinery lubrication, 2000.

${ }^{3} \mathrm{H}$ Wohltjen, NL Jarvis, M Klusty, N Gorin, C Fleck, G Shay, A Smith, 'Solid state microsensors for lubricant condition monitoring: II. Total base number.' Lubricant Engineering, Volume 5, pages:861-866, 1994.

${ }^{4} \mathrm{~V}$ F Lvovich and M F Smiechowskia, 'Iridium oxide sensors for acidity and basicity detection in industrial lubricants', Sensors and Actuators B: Chemical, Volume 96, Issue 1, Pages 261-267, 2003.

${ }^{5}$ A Agoston,C Ötsch,J Zhuravleva, B Jakoby, 'An IR-absorption sensor system for the determination of engine oil deterioration', In: Proceedings of IEEE sensors conference, Volume 1, Pages 463-436, 2004.

${ }^{6}$ FL Dickert, P Forth, PA Lieberzeit, G Voigt, 'Quality control of automotive engine oils with mass-sensitive chemical sensor-QCMs and molecularly imprinted polymers', Journal of Analytical Chemistry, Volume 366, Issue 8, pages $802-806,2000$.

${ }^{7}$ VF Lvovich, MF Smiechowski, 'Impedance characterization of industrial lubricants', Electrochimica. Acta. Volume 51, pages 1487-1496, 2006.

${ }^{8}$ MF Smiechowski, VF Lvovich, 'Electrochemical monitoring of water-surfactant interactions in industrial lubricants', Journal of Electro-analytical Chemistry, Volume 534, Issue 2, pages 171-180, 2002.

${ }^{9}$ SS Wang, HS Lee, 'The application of AC impedance technique for detecting glycol contamination in engine oil', Sensors Actuat. B, Volume 40, pages 193-200, 1997.

${ }^{10} \mathrm{C}$ Ulrich, H Petersson, H Sundgren, F Bjorefors, C Krantz-Rulcker, 'Simultaneous estimation of soot and diesel contamination in engine oil using electrochemical impedance spectroscopy', Sensors and Actuators B: Chemical, Volume 127, Issue 2, Pages 613-618, 2007.

${ }^{11} \mathrm{KN}$ Allahar, DP Butt, ME Orazem, HA Chin, G Danko, et al., 'Impedance of steels in new and degraded ester based lubricating oil', Electrochim. Acta., Volume 51, pages 1497-1504, 2006.

${ }^{12}$ C Ulrich, D Louthander, P Martensson, A Kluftinger, et al. 'Evaluation of industrial cutting fluids using electrochemical impedance spectroscopy and multivariate data analysis', Talanta, Volume 97, pages 468-472, 2012.

${ }^{13} \mathrm{http}: / /$ www.cambridgeviscosity.com/process-sensors; [accessed April 2013].

${ }^{14}$ LB Mauric, B Maurice, JR Parkinson, WB Spillman. 'Magnetic debris monitoring using magneto-optic sending. U.S. patent 5 (214) 377 B1, 1993.

${ }^{15}$ J Heremans, SC Wang, T Schroeder, L Nagy, 'Diesel engine lubricating oil contaminant sensors method', U.S. Patent Application Publication U.S. 2004/0036487, 2004.

${ }^{16}$ NL Jarvis, H Wohltjen, M Klusty, 'Solid-state microsensors for lubricant condition monitoring. Part I: Fuel dilution meter. Lubricant Engineering: Volume 50, Issue 9, pages: 689-693, 1994.

${ }^{17} \mathrm{http} / / /$ www.paj.dk/english/Cases/Water-In-Oil-sensor.asp; [accessed April 2013].

${ }^{18}$ A Mujahid \& FL Dickert, 'Monitoring automotive oil degradation: analytical tools and on-board sensing technologies', Anal. Bioanal. Chem. Volume 404, pages 1197-1209, 2012.

${ }^{19}$ PJE Brignell, NM White, AWJ Cranny, 'Sensor applications of thick-film technology', IEEE Proceedings, Volume 135, pages 77-84, 1988.

${ }^{20}$ JA Mihell, JK Atkinson, 'Planar thick-film pH electrodes based on ruthenium dioxide hydrate', Sensors and Actuators B-Chemical, Volume 48, pages 505-511, 1998.

${ }^{21} \mathrm{M}$ Glanc-Gostkiewicz, et al., 'Performance of miniaturised Thick-Film solid state $\mathrm{pH}$ sensors'. Sensors and Actuators A: Physical, 2013.

${ }^{22}$ M Soleimani, M Sophocleous, M Glanc, J Atkinson, L Wang, RJK Wood, RI Taylor, 'Engine oil acidity detection using solid state ion selective electrodes', Tribology International, Volume 65, September 2013, Pages 48-56.

${ }^{23}$ V F Lvovich, 'Impedance Spectroscopy- Applications to Electrochemical and Dielectric Phenomena', John Wiley \& Sons, USA, 2012.

${ }_{24}$ PJ Holmes, RG Loassby, 'Handbook of Thick Film Technology', Electochemical Publications; 1976.

${ }^{25}$ JA Mihell, JK Atkinson, 'Planar thick-film pH electrodes based on ruthenium Dioxide hydrate'. Sensors and Actuators B-Chemical 1998; 48:505-11.

${ }^{26}$ A Fog, RP Buck. 'Electronic Semiconducting oxides as pH sensors', Sensors and Actuators; 5:137-46, 1984.

${ }^{27}$ Wear Check Africa, 'Effects of temperature on engine lubricating oil', Technical bulletin, Issue 43, Available online 18 April 2013: http://www.wearcheck.co.za/downloads/bulletins/bulletin/tech43.pdf

${ }^{28}$ Kittiwake online resource, 'TAN testing helps to Significantly Reduce Downtime', Available online 21 Sep. 2013: http://www.kittiwake.com/total-acid-number-drop-test 